\title{
Comparison of combined intra-articular and sub-acromial injection with intra-articular injection in adhesive capsulitis Manandhar RR, ${ }^{1}$ D Khanal KR, $^{2}$ iD Khanal H, ${ }^{3}$ iD Gautam S²
}

${ }^{1}$ Rajeev Raj Manandhar, Associate Professor; ${ }^{2}$ Krishna Raj Khanal, Lecturer; ${ }^{3}$ Himal Khanal, Resident; ${ }^{2}$ Saroj Gautam, Lecturer; Department of Orthopaedics, Kathmandu Medical College Teaching Hospital, Sinamangal, Kathmandu, Nepal.

\begin{abstract}
Background: The pain and limitation of shoulder function can disrupt daily activities of patients for months to years. Adhesive capsulitis is considered a self-limiting disease but the duration remains uncertain. The brunt of the disease is focussed on the inflamed joint capsule. On this basis, use of corticosteroid injection is justified. However, injection method is not conclusive.

Objectives: To compare clinical benefits of intra-articular injection alone versus combined intra-articular and subacromial injections in management of adhesive capsulitis.

Methods: Fifty-nine patients with diagnostic criteria for adhesive capsulitis were included in the comparative prospective study from March 2019 to September 2020 after ethical clearance. Patients were divided into two groups; patients who underwent intra-articular (IA) injection alone (Group 1) and those who received both intra-articular and sub-acromial $(I A+S A$ ) injection (Group 2). The injections were landmark guided. Patients were followed up at three, six, and 12 weeks. Pain was recorded using visual analogue scale (VAS) and subjective function using Constant-Murley score.

Results: Twenty-eight patients were included in Group 1 (IA) and 31 in Group 2 (IA+SA). Thirty-six patients were female (18 each in Group 1 and Group 2) and 23 patients were male (Group $1=13$; Group $2=10$ ). In the twelfth week, VAS score was reduced in both the groups. On comparing the mean value of Constant-Murley score between the two groups there is significant difference in value recorded at the sixth and twelfth week.

Conclusion: The IA+SA injection provides significant reduction in pain and better function in the short term over the IA injection.
\end{abstract}

Key words: Adhesive capsulitis; Corticosteroid; Injection.

Access this article online

Website: www.jkmc.com.np

DOI: https://doi.org/10.3126/jkmc.v10i1.38969

\section{HOW TO CITE}

Manandhar RR, Khanal K, Khanal H, Gautam S. Comparison of combined intra-articular and sub-acromial injection with intraarticular injection in adhesive capsulitis. J Kathmandu Med Coll. 2021;10(1):33-8.

\section{Address for correspondence}

\section{Dr. Rajeev Raj Manandhar}

Associate Professor, Department of Orthopaedics,

Kathmandu Medical College Teaching Hospital,

Sinamangal, Kathmandu, Nepal

E-mail: rajeevrajmanandhar@gmail.com

Copyright $\odot 2021$ Journal of Kathmandu Medical College (JKMC)

ISSN: 2019-1785 (Print), 2091-1793 (Online)

\section{INTRODUCTION}

dhesive capsulitis is characterised by painful, gradual Aloss of both active and passive glenohumeral motion resulting from progressive fibrosis and ultimate contracture of glenohumeral joint capsule. ${ }^{1}$ Although considered self-limiting, pain and limitation can persist for more than seven years. ${ }^{2,3}$ It is seen commonly in women and diabetic patients. ${ }^{4}$

Underlying cause remains uncertain and pathology is based on concept of synovial inflammation, joint capsule being main pathology, hence intra-articular steroid injection can be justified for treatment. ${ }^{5}$ Joint injection should be planned after other therapeutic interventions like non-steroidal anti-inflammatory drugs, physical therapy, and activity modification have been tried. Corticosteroids participate in numerous physiological pathways, including inflammation and carbohydrate 
metabolism. They reduce pain and inflammation by inhibiting inflammation and prostaglandin production. Intra-articular steroid injection is considered an accepted treatment, however, not enough evidence exists to draw conclusions regarding which injection method: intra-articular (IA) versus sub-acromial injection (SA) is superior. $^{6}$

Since adhesive capsulitis can occur with accompanying tendinitis and bursitis, combination of IA and SA injections would address both capsulitis and subacromial pathology relieving patient's pain and improving their quality of life. Thus, objective was to compare clinical benefits of intra-articular injection alone versus combined intra-articular and sub-acromial injections in management of adhesive capsulitis.

\section{METHODOLOGY}

A comparative prospective study was performed on adult patients with adhesive capsulitis from March 2019 to September 2020 for a period of one and half years in Kathmandu Medical College Teaching Hospital. Ethical clearance was taken from the hospital ethical committee and written informed consent was taken from all patients (Ref. 2005201916). Fifty-nine patients were included in the study by convenience sampling. The diagnostic criteria for adhesive capsulitis, commonly used in previous studies was selected for the study. ${ }^{8-10}$ According to this criterion, a patient was diagnosed as having adhesive capsulitis when the patient's range of motion was decreased $>30$ degrees on two planes based on normal range of motion (forward flexion 180 degrees, extension 50 degrees, abduction 180 degrees, external rotation 90 degrees, internal rotation 90 degrees). ${ }^{11}$

Plain radiographs were obtained (true antero-posterior and lateral Y scapular view). Patients were excluded if they had secondary adhesive capsulitis and previous corticosteroid injections on the affected shoulder. Magnetic resonance imaging (MRI) was not routinely ordered, but patients who had symptoms and signs of rotator cuff tear were excluded. Patients not improving with physiotherapy and analgesics after four weeks were included in the study.

The patients were divided into two groups; patients who underwent an intra-articular (IA) injection alone were kept in Group 1 and those who received both intra-articular and sub-acromial $(I A+S A)$ injection were categorised as Group 2. The patients were divided into two groups on the basis of odd and even hospital numbers. The odd numbers were placed in Group 1 and even in Group 2.
With the patient in a sitting position the injections were administered taking strict aseptic precautions. A solution of corticosteroid and local anaesthetic composed of 2 $\mathrm{ml}(80 \mathrm{mg}$ ) Methylprednisolone acetate and $4 \mathrm{ml}$ of $2 \%$ Xylocaine was prepared. In the IA+SA group (Group 2), half of the mixture was injected into the $I A$, and the other half was injected into the SA space. The IA injection was administered using the posterior approach. The coracoid process, posterior, and lateral margins of the acromion were palpated. The site of the injection was $2 \mathrm{~cm}$ below and medial to the posterolateral point of the acromion. The needle was directed towards the coracoid process and advanced until the capsule was penetrated. In Group 2, the SA injection was administered using the lateral approach. The spine of scapula was palpated and followed laterally where it forms the acromion process. The lateral edge of acromion was palpated and the needle was placed about $2 \mathrm{~cm}$ inferior in the undersurface and advanced with slight superior angulation just parallel to the acromion into the subacromial space. Following the injection, oral analgesics in the form of non-steroidal anti-inflammatory drugs, combination of tramadol, paracetamol or codeine phosphate and paracetamol were prescribed to reduce the pain of the post injection flare for three days.

The patients were followed up at three, six and twelve weeks. Pain was recorded using visual analogue scale (VAS) and subjective function using the ConstantMurley score. The range of motion was assessed with a goniometer. The physiotherapy sessions began after one week in both groups.

The collected data was charted on Microsoft Excel 2013. Statistical package for the social sciences (SPSS) Statistics for Windows, version 12.0 (SPSS Inc., Chicago, III., USA) was used for the analysis of data. Patient characteristics were recorded on the first visit to the hospital. Quantitative data were expressed in terms of mean and standard deviation. The outcome between two groups was compared using an "independent sample t-test". The outcome between two groups was measured by comparing the mean value of Constant-Murley score of shoulder and VAS score.

\section{RESULTS}

Fifty-nine patients were included in the study, among them 28 patients were included in Group 1 (IA) and 31 in Group $2(\mathrm{IA}+\mathrm{SA})$. Thirty-six patients were female (18 each in Group 1 and Group 2) and 23 patients were male (Group 1 = 13; Group $2=10$ ). The mean time from which symptoms began was 20.21 days in Group 1 and 20.68 
days in Group 2. The mean \pm SD age of Group 1 was $51.21 \pm 7.1$ years and Group 2 was $54.65 \pm 7.9$ years. The demographic variables of both the groups are shown in Table 1.

The baseline mean VAS score in Group 1 (IA only) was $8.79 \pm 0.63$ whereas it was $8.90 \pm 0.65$ in Group $2(I A+S A)$. Similarly, baseline Constant-Murley score was $29.82 \pm$ 2.91 in Group 1 and $28.06 \pm 2.25$ in Group 2. There was a significant reduction in VAS score in Group 1 by 6.65 and 6.77 in Group 2 when analysed on the third week of follow up ( $p<0.05)$. The VAS score was further reduced in both groups, the mean VAS score was $2.04 \pm 1.03$ in Group 1 and $1.81 \pm 0.91$ in Group 2 on the sixth week follow-up from baseline ( $p<0.05)$. On final follow up, which was set at twelfth week, VAS score increased in both the groups with mean value of $3.18 \pm 1.36$ in Group 1 and $2.06 \pm 1.06$ in Group 2 however it was still significantly lower than baseline value $(p<0.05)$.

When VAS score was compared between the two groups there was not a significant difference from baseline to sixth week whereas on final follow up VAS score in Group 1 is 3.18 as compared to 2.06 in Group 2 ( $p<0.05$ ).
The mean Constant-Murley scores at baseline were comparable between the two groups with mean values of $29.82 \pm 2.9$ in Group 1 and $28.06 \pm 2.25$ in Group 2. There was a significant increase in mean ConstantMurley score in both groups on the third week of followup with mean value of $66.36 \pm 3.5$ in Group 1 and $67.29 \pm$ 3.8 in Group 2 respectively ( $p<0.05)$.

On comparing the mean values of Constant-Murley score between the two groups there is significant difference in value recorded at the sixth and twelfth week. The Constant-Murley score is $66 \pm 3.5$ in Group 1 and $69.61 \pm$ 2 in Group 2 at sixth week ( $p<0.05$ ) whereas it is $69.14 \pm$ 2.2 in Group 1 and $72.35 \pm 1.7$ in Group 2 at twelfth week ( $p<0.05)$. Correlation between duration of symptoms with both VAS score and Constant-Murley score at 12th week was analysed using Pearson correlation coefficient. There was a positive correlation between duration of symptoms and VAS score $(r=+0.587)$ which meant that with increasing duration of symptoms there was higher VAS score. When correlation between duration of symptoms and Constant-Murley score was analysed negative correlation was found $(r=-0.192)$ and lower Constant-Murley score at twelfth week follow-up (Figure 1, 2).

Table 1: Demographic variables of both age groups

\begin{tabular}{|c|c|c|c|c|c|}
\hline Type of injection & & Number of patients & Minimum & Maximum & Mean \pm SD \\
\hline \multirow{4}{*}{$\begin{array}{l}\text { Group } 1 \\
\text { (IA) }\end{array}$} & Age (years) & 28 & 38 & 63 & $51.21 \pm 7.1$ \\
\hline & Sex & M13 F18 & & & \\
\hline & Side & L16 R15 & & & \\
\hline & $\begin{array}{l}\text { Duration of symptoms } \\
\text { (months) }\end{array}$ & 28 & 6 & 72 & $20.21 \pm 18.1$ \\
\hline \multirow{4}{*}{$\begin{array}{l}\text { Group } 2 \\
(I A+S A)\end{array}$} & Age (years) & 31 & 39 & 68 & $54.65 \pm 7.9$ \\
\hline & Sex & M10F18 & & & \\
\hline & Side & L18 R10 & & & \\
\hline & $\begin{array}{l}\text { Duration of symptoms } \\
\text { (months) }\end{array}$ & 31 & 6 & 68 & $20.68 \pm 15.5$ \\
\hline
\end{tabular}

Table 2: VAS score chart after injections

\begin{tabular}{lccc}
\hline VAS & Group 1 (IA) & Group 2 (IA+SA) & p-value \\
\hline Pre-injection & 8.78 & 8.90 & 0.485 \\
Three weeks & 2.21 & 2.12 & 0.962 \\
Six weeks & 2.03 & 1.83 & 0.369 \\
Twelve weeks & 3.17 & 2.16 & 0.01 \\
\hline
\end{tabular}


Table 3: Constant-Murley score chart

\begin{tabular}{lccc}
\hline Constant-Murley score & Group 1 (IA) & Group 2 (IA+SA) & p-value \\
\hline Pre-injection & 29.82 & 28.16 & 0.012 \\
\hline Three weeks & 66.21 & 67.29 & 0.333 \\
\hline Six weeks & 65.89 & 69.61 & 0.001 \\
\hline Twelve weeks & 69.10 & 72.41 & 0.001 \\
\hline
\end{tabular}

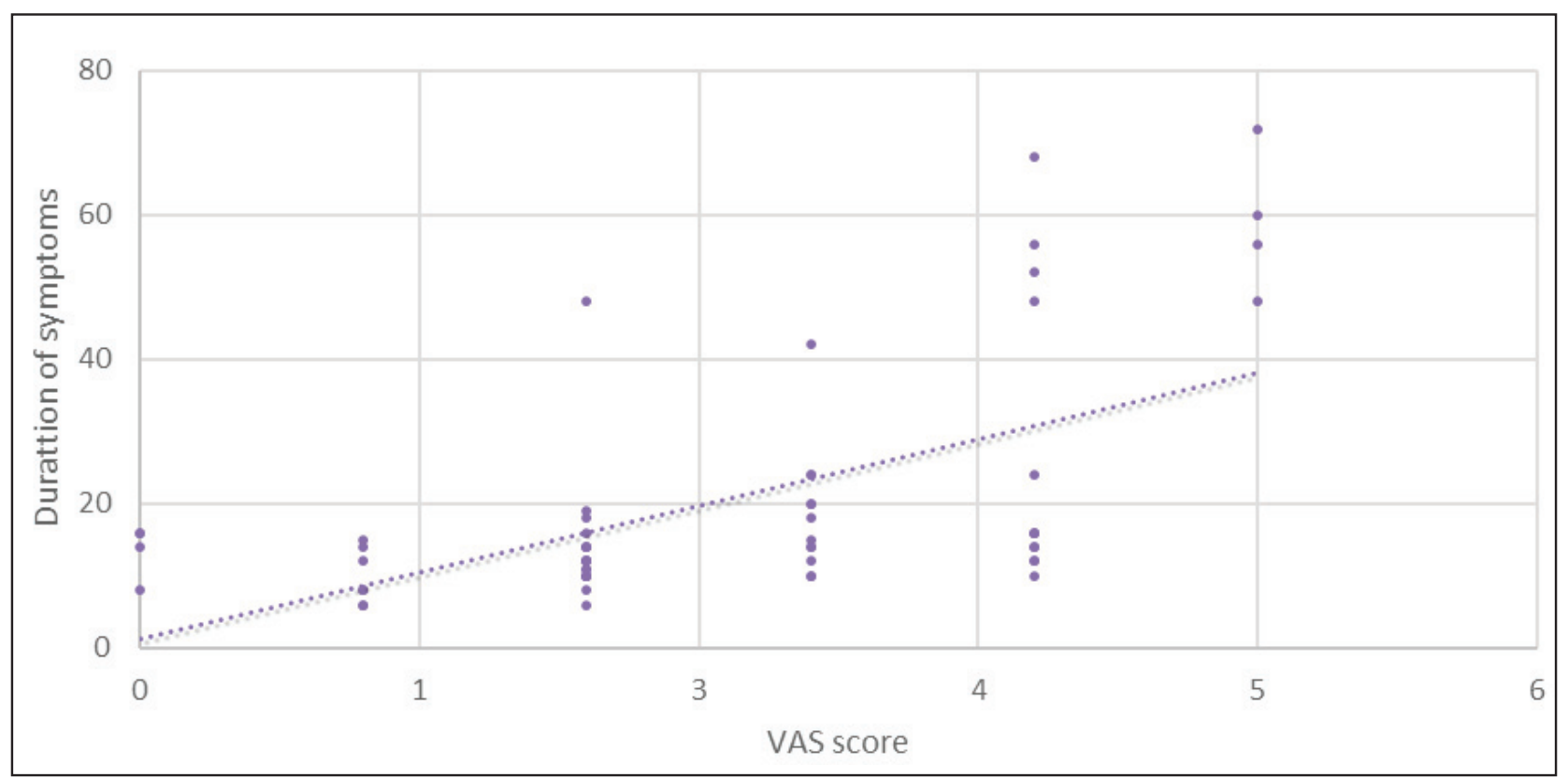

Figure 1: VAS score and duration of symptoms

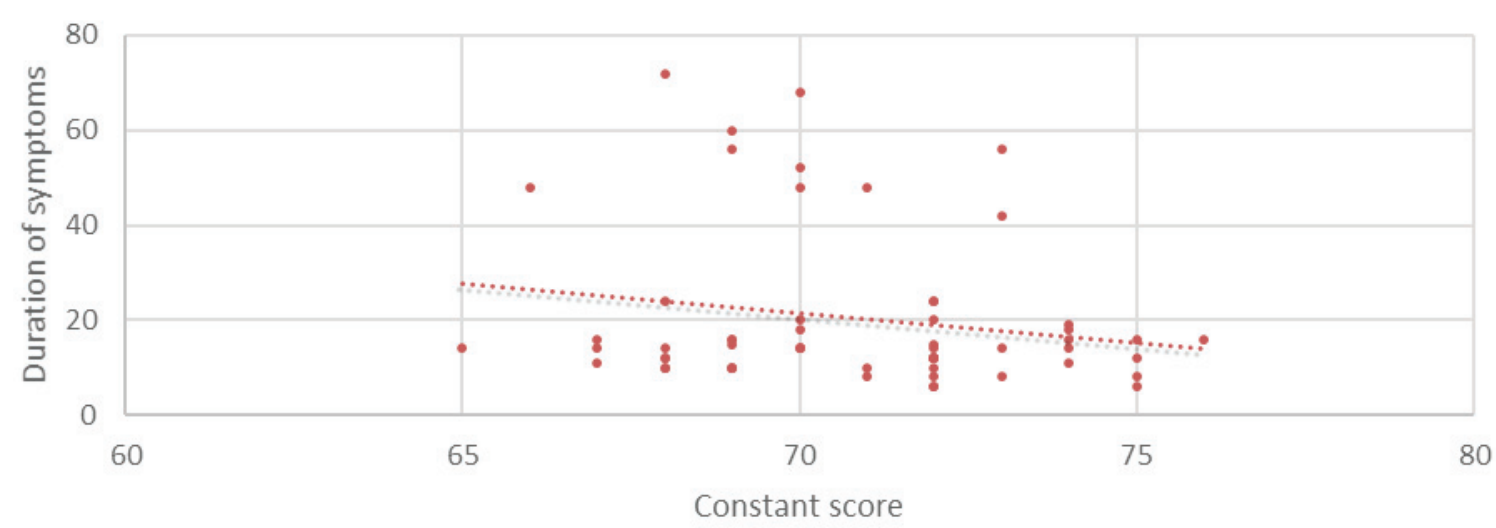

Figure 2: Constant-Murley score and duration of symptoms

\section{DISCUSSION}

Corticosteroid injection is considered to be a well-known and accepted treatment for adhesive capsulitis. Based on the concept of synovial inflammation for the pathology of adhesive capsulitis, the joint capsule can be the main pathology. ${ }^{5}$ Many studies compare IA and SA injections and there is not enough evidence to draw conclusions as to which injection method is superior. ${ }^{11}$ Although corticosteroid injection is a commonly used therapy for adhesive capsulitis, there are only a few studies that compare the efficacy of IA and IA+SA injections. 
The pathology of adhesive capsulitis affects not only the synovium of the joint, but also the rotator cuff, rotator interval and the coraco-humeral ligament. Injection into the SA space can reach up to the latter structures involved in adhesive capsulitis. There is limited literature available on use of SA injections in adhesive capsulitis. ${ }^{6}$

Andrieu et al found that the SA space is almost invariably involved in adhesive capsulitis and suggested an adjuvant SA corticosteroid injection in patients who do not respond to an IA injection. Rotator interval and coraco-humeral ligaments are the chief structures now believed to be involved in adhesive capsulitis ${ }^{12,13}$ and often there is accompanying tendinitis or bursitis. ${ }^{7}$ Both these structures are essentially extra-articular. ${ }^{6}$

Shin et al. ${ }^{14}$ studied four groups with injections in SA, $I A, I A+S A$ and no injections. They found significant short-term benefit of corticosteroid injections over only physiotherapy but there were no differences in functional outcomes between patients receiving only IA or SA injections or a combination of the two. Similar findings were shared by Oh et al. ${ }^{5}$ and Rizk et al..$^{15}$ This study showed a significant increase in functional outcome at the third week in both groups. In comparison of the two groups at twelve weeks, the results were better in the IA+SA group.

Oh et al. ${ }^{5}$ compared 37 patients receiving IA injections with 34 patients receiving SA corticosteroid injections for adhesive capsulitis. There was a significant reduction in pain scores in both the groups, though the patients receiving IA injections had lower pain scores at three weeks following injections. There was no difference in pain scores at six and twelve weeks. In our study, there was a significant reduction in VAS score in the third week in both groups, which further reduced at the sixth week and increased slightly at twelfth week.

Any beneficial effect of steroid injections is likely due to its anti-inflammatory effect. Accuracy of the injection is of utmost importance as inaccurate placement of steroid may result in a partial response. Henkus et al. reported that 62.5 to $76 \%$ of SA injections were accurately placed when given blind, the intended target being the subacromial bursa. Injections isolated to the subacromial bursa resulted in significantly decreased pain and improved functional scores, whereas injection of other structures resulted in increased pain scores. ${ }^{16}$ Eustace et al. ${ }^{17}$ reported $29 \%$ (four out of 14 ) of SA and $42 \%$ (10 out of 24) of IA injections were accurately placed when given blind. There was also a positive correlation between clinical outcome and accurately placed injections. Our study was performed using landmark based injections so better results seen in the IA+SA group could be due to the accuracy of one of the injections if not both.

Ahn et al. ${ }^{11}$ studied whether early presentation and early injection were of benefit and was related to the stage of the disease, as in the first and second stage, synovitis or inflammation is dominant, and the injection had better results and in the later stages when fibrosis was dominant, the role of injection was reduced. Symptoms of pain presenting within three months (the first and second stage) recovered better as they were in the early stage of inflammation. ' While later in the disease, fibrosis develops and the role of steroid injection becomes limited. In our study, we found that there was a positive correlation between duration of symptoms and VAS score after injection at 12 weeks which indicates that shorter the duration of symptoms better the pain relief.

On the basis of the results obtained from our study, corticosteroid injections resulted in early pain relief. However, the pain relief was not consistent as the effects were not sustained at twelve weeks. These data suggest that corticosteroid injections are helpful for pain relief in only the short term. The comparison between the groups at the final assessment shows that the IA+SA group fared significantly better in terms of pain and function. Such an outcome suggests structures beyond the glenohumeral joint capsule may also have a role in the functional limitation in Adhesive capsulitis. This indicates that although the glenohumeral joint is a major site in pathogenesis, the SA space may be a contributing site.

\section{CONCLUSION}

Corticosteroid injection to treat adhesive capsulitis; provides significant pain relief especially in the early stages when pain is the predominant presentation. The combination of the IA+SA injection provides better pain control and functional outcome.

Conflict of interest: None

Source(s) of support: None 


\section{REFERENCES}

1. Neviaser AS, Hannafin JA. Adhesive capsulitis: A review of current treatment. Am J Sports Med. 2010 Nov;38(11):2346-56. [PubMed | Full Text | DOI]

2. Vastamäki H, Kettunen J, Vastamäki M. The natural history of the idiopathic frozen shoulder: A 2- to 27-year followup study. Clin Orthop Relat Res. 2012 Apr;470(4):1133-43. [PubMed | Full Text | DOI]

3. Hand C, Clipsham K, Rees JL, Carr AJ. Long-term outcome of frozen shoulder. J Shoulder Elbow Surg. 2008 Mar-Apr;17(2):231-6. [PubMed | Full Text | DOI]

4. Siegel LB, Cohen NJ, Gall EP. Adhesive capsulitis: A sticky issue. Am Fam Physician. 1999 Apr;59(7):184352. [PubMed | Full Text]

5. Oh JH, Oh CH, Choi J. Comparison of glenohumeral and subacromial steroid injection in primary frozen shoulder: A prospective, randomised short-term comparison study. J Shoulder Elbow Surg. 2011 Oct;20(7):1034-40. [PubMed | Full Text | DOI]

6. Goyal T, Singh A, Negi P, Kharkwal B. Comparative functional outcomes of patients with adhesive capsulitis receiving intra-articular versus subacromial steroid injections: case-control study. Musculoskelet Surg. 2019 Apr;103(1):31-5. [PubMed | Full Text | DOI]

7. Tallia AF, Cardone DA. Diagnostic and therapeutic injection of the shoulder region. Am Fam Physician. 2003 Mar 15;67(6):1271-8. [PubMed | Full Text]

8. Buchbinder R, Green S, Forbes A, Hall S, Lawler G. Arthrographic joint distension with saline and steroid improves function and reduces pain in patients with painful stiff shoulder: Results of a randomised, double blind, placebo controlled trial. Ann Rheum Dis 2004 Mar;63(3):302-9. [PubMed | Full Text | DOI]

9. Warner JJ. Frozen shoulder: Diagnosis and management. J Am Acad Orthop Surg 1997 May;5(3):130-40. [PubMed | Full Text | DOI]
10. Yoon SH, Lee HY, Lee HJ, Kwack KS. Optimal dose of intra-articular corticosteroids for adhesive capsulitis: A randomised, triple-blind, placebo-controlled trial. Am J Sports Med 2013 May;41(5):1133-9. [PubMed | Full Text | DOI]

11. Ahn JH, Lee DH, Kang $H$, Lee MY, Kang DR, Yoon $\mathrm{SH}$. Early intra-articular corticosteroid injection improves pain and function in adhesive capsulitis of the shoulder: 1-year retrospective longitudinal study. PM R 2018 Jan;10(1):19-27. [PubMed | Full Text | DOI]

12. Kim KC, Rhee KJ, Shin HD. Adhesive capsulitis of the shoulder: Dimensions of the rotator interval measured with magnetic resonance arthrography. J Shoulder Elbow Surg. 2009 May-Jun;18(3):437-42. [PubMed | Full Text | DOI]

13. Neer CS 2nd, Satterlee CC, Dalsey RM, Flatow EL. The anatomy and potential effects of contracture of the coracohumeral ligament. Clin Orthop Relat Res. 1992 Jul;280:182-5. [PubMed | Full Text]

14. Shin JS, Lee SY. Efficacies of corticosteroid injection at different sites of the shoulder for the treatment of adhesive capsulitis. J Shoulder Elbow Surg. 2013 Apr;22(4):521-7. [PubMed | Full Text | DOI]

15. Rizk TE, Pinals RS, Talaiver AS. Corticosteroid injections in adhesive capsulitis: investigation of their value and site. Arch Phys Med Rehabil. 1991 Jan;72(1):20-2. [PubMed | Full Text]

16. Henkus HE, Cobben LPJ, Coerkamp EG, Nelissen $\mathrm{RGHH}$, van Arkel ERA. The accuracy of subacromial injections: A prospective randomised magnetic resonance imaging study. Arthroscopy. 2006 Mar; 22(3):277-82. [PubMed | Full Text | DOI]

17. Eustace JA, Brophy DP, Gibney RP, Bresnihan B, FitzGerald O. Comparison of the accuracy of steroid placement with clinical outcome in patients with shoulder symptoms. Ann Rheum Dis. 1997 Jan; 56(1):59-63. [PubMed | Full Text | DOI] 